\title{
Obesity a multifactorial medical problem, presentation to treatment: A Systematic Review.
}

\footnotetext{
1. MS (Biochemistry and Molecular Biology)

Lecturer Biochemistry

Hazara University, Mansehra Pakistan.

2. MS Biotechnology Biological Sciences Islamic International University, Islamabad, Pakistan

3. M.Phil (Biochemistry) Assistant Professor Biochemistry Hazara University, Mansehra, Pakistan.
}

Correspondence Address:

Ehsan Humayun Lecturer in Biochemistry

Hazara University, Mansehra, Pakistan

ehsanhamayun@hu.edu.pk

Article received on:

31/03/2020

Accepted for publication:

20/06/2020

\begin{abstract}
Ehsan Humayun 1 , Uroba Ali $^{2}$, Nodia Shujaat ${ }^{3}$
ABSTRACT... OBJECTIVE: The aim of the current article is to critically review the current literature on the presentation and treatment of obesity as it is one of the major health concerns, that can affect the metabolism of an individual by causing some of the most serious and devastating medical complications. Results: It affects the quality of normal human body function. During the process of aging, it causes weakness in overweight and obese individuals. Environment, diet, genetics, maternal factors are some of the major causes involved in the progression of obesity. A number of genes involved in metabolism, adipogenesis, and lipolysis have a proven role in weight gain. Obesity is associated with various diseases such as type II diabetes, cardiovascular disorder, metabolic abnormalities, cancer, cataract, and Urinary Incontinence, etc. Treatment of obesity is important, but treatments under consideration are controversial as obesity causes health risks related to the increased body mass and weight loss in the older population. Conclusion: Moreover, the therapies involved in weight loss have to keep an eye on the side effects of instant weight loss for the human body.
\end{abstract}

Key words: $\quad$ Adipogenesis, BMI, Genes, Genetics, Obesity.

Article Citation: Humayun E, Ali U, Shujaat N. Obesity a multifactorial medical problem, presentation to treatment: A Systematic Review. Professional Med J 2021; 28(1):1-8. https://doi.org/10.29309/TPMJ/2021.28.01.4689

\section{INTRODUCTION}

Now a day individuals living in an industrialized world, have one of the most prevalent condition, increasing quickly is obesity. Biology of obesity is quite complexas it is under the influence of multiple factors i-e roles of genes, climate, environment, diet, living style and their combined effects. ${ }^{1}$ The gain or increase in fat of the body is known as obesity. On the basis of different studies, obesity is defined primarily as an increase in the weight and circumference of waist. Such parameters provide knowledge about the degree and stage of obesity. A person is considered as obese if the $\mathrm{BMI}$ of a person is $30 \mathrm{~kg} / \mathrm{m}^{2}$ and overweight if Body Mass Index is equal or higher that $25 \mathrm{~kg} / \mathrm{m}^{2}$ according to World health organization. There are a lot of other means cited in literature to define obesity. Fat distribution with reference to "waist to hip ratio" is recorded as obesity. ${ }^{2}$ One third of the US and 10-25 percent of the European population is affected by Obesity, this number is increasing continuously. It is estimated that, in the United States, every year there are more than 0.3 million deaths are reported due to obesity. Poor diet including low nutrient, but maximum caloric diet and less physical activity are some of the risk factors for obesity. It also results in several medical conditions such as heredity diseases, age, gender, endocrine imbalance and genetic alterations. ${ }^{3}$ In both male and female, effect of obesity and overweight with increasing age is different in different regions such as Africans and American population; this rate is higher but relatively lowers in Asian population. It is highly frequent in women and peoples with low socioeconomic status. Another factor that causes increase in weight is the diet and exercise behaviors that result in obesity related diseases. Malnutrition, premature death, birth defects, malignancies, CVD, thrombosis, diabetes, depression, infertility, chronic venous insufficiency, renal disorder, gout, loss of immunity and respiratory efficiency, fatty liver, arthritis, loss of sleep and stroke are some of medical disorders that are linked to obesity. ${ }^{4}$ 


\section{Prevalence of Obesity}

Over the past few decades, the increased obesity incidence has been observed in different age groups. By comparing the results of obesity in the US, during the late $20^{\text {th }}$ century and in the start of the $21^{\text {st }}$ century, almost 10 years incidence of obesity has been increased in different age group. Statistics from different population surveys showed that the probability of being obese increases during the age of 20 to 60 years and then declines later. Older people like 80 years of age are less prone to it. The reason behind this low rate of obesity in these people is the benefit of being lean as the probability of obesity decreases after 60 years of age. ${ }^{5}$ National statistics of obesity in male and female is shown in Table-l.

\section{Pathogenesis}

Energy intake and utilization are the parameters that are involved in the determination of FM (fat mass). There are two important parameters that are involved in the increase of total fat mass i-e an elevated intake of energy as well as decline in total energy expenditure. Most of the studies revealed that age has no particular effect on energy intake with aging, so it is an indirect change in the overall energy expenditure that declines with age and results in increased body fat mass. ${ }^{6}$

Fat accumulation, free fat mass reduction and energy imbalance are enhanced by the hormonal changes induced by aging. Decreased $\mathrm{GH}$ (growth hormone) secretion, reduced sensitivity for TH (thyroid hormone), leptin resistance and less serum testosterone are associated with aging. Leptin resistance results in increased appetite while TH causes oxidative bursts. With increasing age decrease in the production of $\mathrm{GH}$ and testosterone results in the accumulation of fat mass and reduction of free fat mass. ${ }^{7}$

\section{Genes and Obesity}

There are hundreds of genetic diverse regions and positive natural selection regions in the human genome. Alteration in diet, communicable diseases and adaptations are the reasons for certain positive mutations in human body. Sometimes obesity occurs due to the mutation in a single gene for example MC4R gene that encodes for Melanocortin 4 receptor present at 18q22. A mutation in MC4R results in loss of its function is present in prevalence of $<5 \%$ in obese persons. Children affected by this mutation feel extreme hunger and become obese due to overeating habit. ${ }^{8}$ Following are the major genes involved in regulation with obesity as in Table-II.

\begin{tabular}{|c|c|c|c|}
\hline \multirow[t]{2}{*}{ States } & \multirow{2}{*}{$\begin{array}{c}\text { Age } \\
\text { Ran- } \\
\text { ges }\end{array}$} & \multicolumn{2}{|c|}{$\begin{array}{l}\text { Overall Obesity } \\
\text { Prevalence }\end{array}$} \\
\hline & & Men & Women \\
\hline Albania (1986) & $\geq 25$ & 22.8 & 35.6 \\
\hline Pakistan (2004) & $18-65$ & 25 & 70 \\
\hline Pakistan (2014) & $20-60$ & 34 & 60 \\
\hline Bahrain (1998-99) & $19+$ & 23 & 34 \\
\hline Brazil (1996) & $\geq 20$ & 8.4 & 12 \\
\hline Canada (2000-01) & $20-64$ & 16 & 14 \\
\hline Chile (1988) & $\geq 15$ & 13.3 & 22.9 \\
\hline Chile (2001) & $24-64$ & 15.7 & 23.1 \\
\hline China (1990-2000) & $20+$ & 2 & 4 \\
\hline China(1984) & $18-49$ & 15.3 & 17.1 \\
\hline Cook Islands (1998) & $17+$ & 41 & 50 \\
\hline Cuba (1996) & $20-59$ & 5.1 & 12.2 \\
\hline Denmark (1982) & $30-60$ & 10 & 9 \\
\hline Denmark (1994) & $16+$ & 9 & - \\
\hline Egypt (1998-99) & $18-60$ & 13 & 33 \\
\hline Fiji (1993) & $18+$ & 7 & 21 \\
\hline French Polynesia (1995) & $16+$ & 36 & 44 \\
\hline Germany (1998) & $18-79$ & 19 & 22 \\
\hline Ghana (1987-89) & $20-65$ & 1 & 6 \\
\hline India (1990-91) & $\geq 15$ & 4.8 & 7.8 \\
\hline India (1998) & $18+$ & 0.3 & 0.5 \\
\hline Iran (1999) & $15+$ & 6 & 14 \\
\hline Ireland (1997-99) & $18-64$ & 20 & 16 \\
\hline Japan (2001) & $15+$ & 3 & 3 \\
\hline Kuwait (1980-81) & $18+$ & 15 & 30 \\
\hline Kuwait (1998-2000) & $18+$ & 28 & 30 \\
\hline Latvia (1997) & $19-64$ & 10 & 17 \\
\hline Lesotho (1993) & $20-65$ & - & 23 \\
\hline Lithuania (1999) & $20-64$ & 16.2 & 16 \\
\hline Morocco (1998-99) & $18+$ & 4 & 16 \\
\hline Nauru (1994) & $25-69$ & 80 & 79 \\
\hline Norway (1994) & $16-79$ & 5 & 6 \\
\hline Peru (1987) & $\geq 18$ & 16 & 22.7 \\
\hline Philippines (1998) & $20+$ & 2 & 4 \\
\hline Russian Federation (1993) & $19-55$ & 10.3 & 21.7 \\
\hline Samoa (2000) & $25-74$ & 48.7 & 68 \\
\hline Saudi Arabia (1987-92) & $18+$ & 16 & 26 \\
\hline Saudi Arabia (1995) & $18+$ & 13 & 20 \\
\hline Singapore (1998) & $18-69$ & 5 & 7 \\
\hline South Africa (1998) & $15+$ & 9 & 30 \\
\hline Sweden (1996-97) & $16-84$ & 7 & 7 \\
\hline USA (1999-2002) & $16+$ & 26 & 32 \\
\hline Vanuatu (1998) & $20+$ & 12 & 20 \\
\hline
\end{tabular}




\begin{tabular}{|c|c|c|c|}
\hline Gene Abb. & Locus & Gene Type & Function \\
\hline ADIPOQ & $3 q 27.3$ & Protein Coding & Involved in Hormonal and metabolic processes. \\
\hline BMIQ-1 & $7 q 32.3$ & Unknown & ----- \\
\hline BMIQ-2 & $13 q 14$ & Unknown & ----- \\
\hline BMIQ-3 & $6 q 23-25$ & Unknown & ---- \\
\hline BMIQ-4 & $11 q 24$ & Unknown & 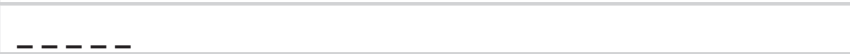 \\
\hline BMIQ-5 & $16 \mathrm{p} 13$ & Unknown & $-\ldots--$ \\
\hline BMIQ-6 & 20pter-p11.2 & Unknown & ----- \\
\hline TMEM-18 & $2 p 25.3$ & Protein Coding & Sequence specific dsDNA and ssDNA binding protein. \\
\hline GNPDA-2 & $4 p 13$ & Protein Coding & $\begin{array}{l}\text { Convert glucosamine-6-P into fructose-6-P and Ammonium. } \\
\text { Variations result in altered BMI and Obesity. }\end{array}$ \\
\hline NEGR-1 & $1 \mathrm{p} 31.1$ & Protein Coding & $\begin{array}{l}\text { Involved in cell adhesion pathway. Variations results in } \\
\text { Obesity andPodoconiosis. }\end{array}$ \\
\hline BDNF & $11 \mathrm{p} 13$ & Protein Coding & Involved in CREB pathway and p70S6K signaling. \\
\hline KCTD-15 & $19 q 13.12$ & Protein Coding & $\begin{array}{l}\text { Involved in Signaling of Sweet Taste and Hepatic ABC } \\
\text { Transporters. Variations results in Obesity. }\end{array}$ \\
\hline SH2B-1 & $16 \mathrm{p} 11.2$ & Protein Coding & Activate various kinases, GFR and cytokine signaling. \\
\hline MTCH-2 & $11 \mathrm{p} 11.2$ & Protein Coding & Involved in differentiation of adipocytes. \\
\hline PCSK-1 & $5 q 15-21$ & Protein Coding & Involves in the hormonal proteolytic activation. \\
\hline NPC-1 & $18 q 11-q 12$ & Protein Coding & Involves in intracellular cholesterol trafficking \\
\hline FTO & $16 q 12.2$ & Protein Coding & Involves in improved food intake. \\
\hline LEP & $7 q 32.1$ & Protein Coding & Synthesized by fat cells. \\
\hline LEPR & $1 \mathrm{p} 31.3$ & Protein Coding & Inhibits appetite when leptin binds. \\
\hline INSIG-2 & $2 q 14.1-q 14.2$ & Protein Coding & Biosynthesis of Fatty acid and cholesterol regulation \\
\hline MC4R & $18 q 22$ & Protein Coding & Stimulation of Hormones and hunger. \\
\hline PCSK-1 & $5 q 15$ & Protein Coding & Insulin regulation. \\
\hline PPARg & $3 p 25.2$ & Protein Coding & Lipid uptake and Fat tissue formation \\
\hline
\end{tabular}

\section{Causes of Obesity}

Though the mystery behind chubbiness is not yet clearly understood, but it is obvious that the person becomes obese when it stores the more energy than the required one. There are many studies regarding the imbalance in energy utilization, but we cannot define the main cause of the prevalence of obesity by a single result. There are many genetic as well as the epigenetic factors that influence the prevalence of obesity. ${ }^{9}$ Under secretion of thyroid hormones and $\mathrm{GH}$ leads to the obesity in children. Leptin deficiency may also cause obesity in children. ${ }^{10}$ Person's environment, culture, lifestyle, eating habits has a greater influence on chubbiness.

\section{a) Genetics}

Parsons and colleagues systematically reviewed the child's early life predictors of adulthood obesity. They also summarized the findings that how the phenotype is inherited. The authors concluded, that 'obesity is inherited, means the offspring's of those parents who were obese in their early adulthood, have more chances to get obese in their adulthood'. Recently it has been confirmed that a significant heritability component are associated with obesity these are the parent's height, BMI, total body fat and weight (kg or pounds). ${ }^{11}$ Mothers' birth-weight is also an important consideration in relation to the offspring birth weight. Maes and collaborators, in their studies, suggested that variations in BMI up to $20-90 \%$ are due to inherited issues. Farooqi in his most recent studies investigated the heritability of $\mathrm{BMl}$ at around $40 \%$ to $70 \% .{ }^{12}$ 


\section{b) Maternal Factors}

Huang and colleagues systematically reviewed; in their studies, they found a co-relation between pre gestational or gestational diabetes with the prevalence of obesity. A study by Highest also provides significant associated results. Many studies reported that the exposure of mother to smoking and childhood obesity are in direct association with obesity. It has been observed through many studies, along with the factors mentioned above; lack of nutrition during earlier pregnancy stages may cause the variations of the endocrine system in terms of structure and function. ${ }^{13}$

\section{ADVERSE EFFECTS OF OBESITY}

\section{1) Mortality}

The survival rate of an individual decreases due to obesity. Result from Framingham Heart Study reveals adults having Body Mass Index $\geq 30$ lived 6-7 years less which are suffering from obesity compared with their normal aged person. ${ }^{14}$ Similarly, there is another study, which concludes the different data sets; these are the NHANES (National Health \& Nutritional Examination Survey) I, II and III. In younger adults due to overweight/ obesity, there is decrease in life expectancy. For example, in white male and female population of 20 to 30 years, having BMI $\geq 45$ life expectancy lost by 13 to 8 years respectively.

Male and female with a BMI $\geq 30$ mostly have a high mortality risk and are considered obese than do those have a BMI: 25.0-29.9. Due to the increasing BMI in adulthood, death rate is relatively less, as compared to older age, concluding that increased BMI is more lethal during old age. There is a misrepresentation of the data as it indicates obesity is less dangerous in older than in younger. ${ }^{15}$

\section{2) Risk Factors Associated with Obesity}

Severe physiological issues as a result of obesity lead to serious problems, especially premature death of an organism. But most of the studies conducted on a middle aged group, reveals that diabetes, hypertension, cardiovascular disease, and osteoarthritis are some of medical complications that increase with time. Hence, different medical complications result from an increase in body weight during middle aged group

\section{a) Metabolic Abnormalities}

Metabolicdisordercomponentsaremoreprevalent in older individuals like increase in abdominal fat, resistant to insulin, the metabolism of glucose, increase of high blood pressure. The incidence of metabolic syndrome is directly related to the age factor and rise periodically after 30 years of age with a peak during 50-70 years in male and during 60-80 years of age in female. According to the CDCP (Centers for Disease Control and Prevention) report in 1998, approximately type 2 diabetes is diagnosed in $12.7 \%$ of the older population after the age of 70 years and there is an $11.6 \%$ increase in number since $1990 .{ }^{16}$ In the older population, hypertension is more common after the age of 65 years, affecting approximately $30-50 \%$ of all people. According to HHP (Honolulu Heart Program) and a survey of JDB (Japanese Data Bank) in older age, obesity is comparatively correlated with hyper blood pressure. In some studies even waist circumference was better than $\mathrm{BMI}$ in predicting hypertension. ${ }^{17,18}$

\section{b) Arthritis}

In the older population main cause of physical disability is Arthritis. Moreover, in older population increased risk of knee osteoarthritis (OA) is resulting from high $\mathrm{BMI}$, as an increase in body weight occur more across knee as a result of increase in weight also, as a result of obesity $O A$ increases by decades, supporting that obesity is the main cause of $O A$. OA after 65 years commonly occurs in female $68 \%$, men $58 \%$ and its symptoms appear usually after age of 40 years. As a result of increase prevalence of $O A$ it causes different changes in the body as its result in overweight of an affected person, which also causes lots of complications particularly on joints. ${ }^{19}$

\section{c) Pulmonary Abnormalities}

PFA (Pulmonary functional abnormality), OSA (obstructive sleep apnea), and OHS (obesity hypo-ventilation syndrome) all are associated with obesity as a result of increase weight on 
chest wall causes respiratory problem difficulty in breathing. In obese men it results in sleep apnea related to weight gain. According to 5 year study data shows that in older, obese person there is rise in RDI (respiratory disturbance index). ${ }^{20}$ An increase of $5 \%$ of BMI in 20 years of women leads to increase in $2 \% \mathrm{RDI}$ and in there is increasing by $27 \%$ of RDI in older obese men of 60 years

\section{d) Urinary Incontinence}

After the age of 65 years $>15-30 \%$ people are affected by urinary incontinence and obesity is the major cause of its increase mainly in older populations, and it is directly linked with high BMI.

\section{e) Cataract}

Cataracts affect $20 \%$ of persons aged. One group study of $40-84$ years and second for 5-14 years shows that increased prevalence of cataract result due to overweight and obesity but the main cause is unknown that obesity is involved in early cataract as different abnormalities that basically result from obesity are involved in the cataracts formation. These abnormalities are elevated circulating inflammatory mediators, resistance to insulin and hyper uric acid. ${ }^{21-22}$

\section{h) Cancer}

Another cause of the complications resulting from obesity is cancer as obesity is linked to certain forms of malignancies/cancer are more prevalent in older populations, for example including bladder cancer, prostate cancers, colon, pancreatic malignancies, renal, breast, bladder, uterine and cervical cancer. According to recent data in old obese female $\geq 60$ years with $\mathrm{BMI} \geq 30$ the frequency of breast cancer is higher than normal women.

\section{i) Cardiovascular Complications}

In the progression of cardiovascular disorder, obesity is one of the major risk factors reported worldwide. Individuals diagnosed as obese or overweight are more prone towards number of medical complications; those are directly in contrast with morbidity and mortality. Along with cardiovascular disorders, it is responsible for the development of coronary heart disease, dyslipdemia and hypertension. Obesity leads to the increase of overall energy and metabolic demands, which directly affects the blood volume and cardiac output. ${ }^{23}$

\section{j) Type 2 Diabetes Mellitus}

The relationship of type 2 diabetes and obesity is in contrast to each other as studies shown that obesity is particularly involved in the pathogenesis of diabetes, that is why the relationship between both disorders is termed as "Diabesity". Studies have revealed that about 3.6 billion individuals are diagnosed with type 2 diabetes and the ratio indicates that almost about $10 \%$ of adult individuals will be affected by 2030 globally. Approximately, 0.35 billion individual deaths are reported due to diabetes due to type 2 diabetes. ${ }^{24}$ Both diabetes type 2 and obesity often coexist, and literature shows that about $60-90 \%$ of individuals are diagnosed with diabetes type 2 are obese.

\section{Treatment}

Weight loss during any age in obese persons can prevent the medical complications, life quality and physical health, but the major reason of therapy can vary across different age groups. In case of young ones and adults the major achievement in weight loss therapy is to prevent and treat the medical issue while improved life quality and physical health are the major achievements in old persons. Muscle and bone mass prevention is the major decider for the approach of therapy used to lose weight in adults and older ones. For weight loss and management current therapies are.

\section{1) Lifestyle Intervention}

Moderate weight loss can be achieved by combining effect of low calorie diet, more physical activity as well as by behavior therapy, which includes self-monitoring (paying closer attention to social system), goal setting (the process of deciding what you want to achieve or what you want someone else to achieve), social support (social relationships) and stimulus control. At the same time with all these things a person can also stay away from the associated risk of weight-loss treatments. Among all energydeficient diet shrinks energy consumption from 500 to $100 \mathrm{kcal} / \mathrm{d}$, which leads to $\approx 400-900 \mathrm{gm} /$ 
wk weight-loss and in 6 months $8-10 \%$ weight loss.

\section{2) Pharmacotheraputic Techniques}

Pharmacotherapy use under random treatments in most randomized controlled trial assessment is conducted for obesity omitted old peoples, other reports comprised few samples of old persons. According to the recent clinical studies, it has been observed that the normal age of persons (subjects) lies in between 34 to 54 years. So, the available data is not enough in older persons to define the efficiency and security of pharmacotherapy in case of obesity. ${ }^{25}$ In obesity Pharmacological agent uses among older patients as a treatment can cause an extra burden among older persons. Sometime it happens many older individuals are also suffering from many other problems and taking medicines. So by using obesity pharmacological treatment there is a chance for non-adherence or errors with other medicines as well. ${ }^{26}$

\section{3) Surgery}

Most efficient treatments in case of weight loss therapy are Bariatric surgery. NIH Conference held in 1991 recommendations for Bariatric surgery was established. The team (panel) decided that people who have morbid obesity (means people of BMI 35.0 to 39.9 along with severe medical complication due to obesity, for example $B M I \geq 40$, CVD, diabetes (Type II), sleep apnea, or depression, there is a chance of success is considered potential for surgical treatment.

\section{4) Drug Treatment}

Treatment with the help of drug can alter the metabolism of the body; it can reduce the intake of food and increase energy consumption. This methodology is the use in accessible and effective drugs uses for the treatment.

\section{4a) Food Intake Control}

\section{(i) Nor-Adrenergic Receptors}

Neuropeptides and Monoamines are recognized as food up taking modulators. Serotonergic and Noradrenergic receptors together provide site for those drugs that are clinically suitable to decrease food intake. The $a_{1}{ }^{-}$and $\beta_{2}$-adrenoceptors activation is also responsible for decreasing food intake in body. On the other hand, in experiments conducted on animals there is the opposite action of $\mathrm{a}_{2}$-adrenoceptor, it elevates body's food intake. When a substance and drug has direct agonist effect to release or block of reuptake norepinephrine (NE), results in activation of receptors where norepinephrine is present. ${ }^{25}$

\section{(ii) Serotonin Receptor System}

There are seven different families of serotonin receptor system; Feeding is directly affected by the stimulation of $5 \mathrm{HT}_{1}$ and $5 \mathrm{HT}_{2}$. Food intake is increased by the activation of the $5-\mathrm{HT}_{1 \mathrm{a}}$ receptor, but it is certainly down regulated so it is not considered in body weight regulation. Classes $\mathrm{HT} 1 \mathrm{~B}$ and $\mathrm{HT} 2 \mathrm{C}$ are involved in down regulation of signal that is involved in increased food intake. ${ }^{26}$

\section{4b) Changes in Metabolism}

Extra fat is used as an indication of obesity. In order to modify and absorbed fat mechanism there a few metabolic schemes that are related to absorption and post absorption processes. A pre absorptive process has a direct effect on digestion and macronutrients absorption used to develop orlistat, it prevents fat digestion and decreases weight.

\section{4c) Elevated Energy Expenditure}

More energy consumption by the help of exercise is an excellent way for dealing with obesity. As well as those medicines having the same effect like exercise are also good approach of treating obesity in pharmaceutical ways.

\section{CONCLUSION}

In the list of public health concerns obesity is one of the major health issue associated with multiple chronic diseases and disorders. Genetic variants that are involved in the person's susceptibility towards obesity are critical to identify as number of persons suffering from obesity are increasing noticeably. Therefore, it is the need of time to use weight loss therapies primarily to improve physical condition and function and secondly preventing and lifting the medical complications in obese persons. Also the consideration of 
adverse effects related to weight loss therapies must be considered to prevent muscle and bone mass.

Copyright@ 20 June, 2020.

\section{REFERENCES}

1. Arner P. Obesity-a genetic disease of adipose tissue? Br J Nutr. 2000; 83(S1):S9-S16.

2. Moyad MA. Current methods used for defining, measuring, and treating obesity. In: Seminars in urologic oncology. 2001. p. 247-56.

3. Swinburn BA, Caterson I, Seidell JC, James WPT. Diet, nutrition and the prevention of excess weight gain and obesity. Public Health Nutr. 2004; 7(1a):123-46.

4. Kenchaiah S, Gaziano JM, Vasan RS. Impact of obesity on the risk of heart failure and survival after the onset of heart failure. Med Clin North Am. 2004; 88(5):127394.

5. Wallace JI, Schwartz RS. Involuntary weight loss in elderly outpatients: Recognition, etiologies, and treatment. Clin Geriatr Med. 1997; 13(4):717-36.

6. Hallfrisch J, Muller D, Drinkwater D, Tobin J, Andres $R$. Continuing diet trends in men: the Baltimore Longitudinal Study of Aging (1961-1987). J Gerontol. 1990; 45(6):M186-M191.

7. Schwartz RS, Schwartz RS. Trophic factor supplementation: Effect on the age-associated changes in body composition. J Gerontol A Biol Sci Med Sci. 1995; 50(Special_Issue):151-6.

8. Choquet H, Meyre D. Genetics of obesity: what have we learned? Curr Genomics. 2011; 12(3):169-79.

9. Eckel RH, Krauss RM. American Heart Association call to action: Obesity as a major risk factor for coronary heart disease. Circulation. 1998; 97(21):2099-2100.

10. Link K, Moëll C, Garwicz S, Cavallin-Ståhl E, Björk J, Thilén $U$, et al. Growth hormone deficiency predicts cardiovascular risk in young adults treated for acute lymphoblastic leukemia in childhood. J Clin Endocrinol Metab. 2004; 89(10):5003-12.

11. Berkowitz RI, Stallings VA, Maislin G, Stunkard AJ. Growth of children at high risk of obesity during the first 6 y of life: implications for prevention-. Am J Clin Nutr. 2005; 81(1):140-6.

12. Farooqi IS, O'Rahilly S. New advances in the genetics of early onset obesity. Nature Publishing Group; 2005.
13. Ravelli G-P, Stein ZA, Susser MW. Obesity in young men after famine exposure in utero and early infancy. N Engl J Med. 1976; 295(7):349-53.

14. Peeters A, Barendregt JJ, Willekens F, Mackenbach JP, Al Mamun A, Bonneux L. Obesity in adulthood and its consequences for life expectancy: A life-table analysis. Ann Intern Med. 2003; 138(1):24-32.

15. Kassirer JP, Angell M. Losing weight-an ill-fated New Year's resolution. Mass Medical Soc; 1998.

16. Harris T, Cook EF, Garrison R, Higgins M, Kannel W, Goldman L. Body mass index and mortality among nonsmoking older persons: The Framingham Heart Study. Jama. 1988; 259(10):1520-1524.

17. Janssen I, Katzmarzyk PT, Ross R. Waist circumference and not body mass index explains obesity-related health risk. Am J Clin Nutr. 2004; 79(3):379-84.

18. Folsom AR, Kushi LH, Anderson KE, Mink PJ, Olson $\mathrm{JE}$, Hong C-P, et al. Associations of general and abdominal obesity with multiple health outcomes in older women: The lowa Women's Health Study. Arch Intern Med. 2000; 160(14):2117-28.

19. Oddis CV. New perspectives on osteoarthritis. Am J Med. 1996; 100(2):10S-15S.

20. Redline S, Schluchter MD, Larkin EK, Tishler PV. Predictors of longitudinal change in sleep-disordered breathing in a nonclinic population. Sleep. 2003; 26(6):703-9.

21. Glynn RJ, Christen WG, Manson JE, Bernheimer J, Hennekens $\mathrm{CH}$. Body mass index: An independent predictor of cataract. Arch Ophthalmol. 1995; 113(9):1131-37.

22. Hiller R, Podgor MJ, Sperduto RD, Nowroozi L, Wilson PW, D'Agostino RB, et al. A longitudinal study of body mass index and lens opacities: The Framingham Studies. Ophthalmology. 1998; 105(7):1244-50.

23. Poirier $P$, Després J-P. Exercise in weight management of obesity. Cardiol Clin. 2001; 19(3):459-470.

24. Whiting DR, Guariguata L, Weil C, Shaw J. IDF diabetes atlas: Global estimates of the prevalence of diabetes for 2011 and 2030. Diabetes Res Clin Pract. 2011; 94(3):311-21.

25. LiZ, Maglione M, TuW, Mojica W, Arterburn D, Shugarman LR, et al. Meta-analysis: Pharmacologic treatment of obesity. Ann Intern Med. 2005; 142(7):532-46. 
26. Haynes RB. Improving patient adherence: state of the art, with a special focus on medication taking for cardiovascular disorders. Compliance in healthcare and research. Amonk NY: Futura Publishing Company. 2001:3-21.

\section{AUTHORSHIP AND CONTRIBUTION DECLARATION}

\begin{tabular}{|c|l|l|}
\hline Sr. \# & Author(s) Full Name & \multicolumn{1}{|c|}{ Contribution to the paper } \\
\hline 1 & Ehsan Humayun & $\begin{array}{l}\text { Conception, design of work, drafting } \\
\text { and final approval of version. }\end{array}$ \\
2 & Uroba Ali & $\begin{array}{l}\text { Drafting, Citations and literature } \\
\text { review. } \\
\text { Conception and final approval of } \\
\text { version. }\end{array}$ \\
\hline
\end{tabular}

